\title{
Bond strength of different endodontic sealers to dentin: push-out test
}

\author{
João Vicente Baroni BARBIZAM ${ }^{1}$, Martin TROPE ${ }^{2}$, Mario TANOMARU-FILHO ${ }^{3}$, Erica Cappelletto Nogueira TEIXEIRA ${ }^{4}$,
} Fabricio Batista TEIXEIRA ${ }^{2}$

\author{
1- DDS, PhD, Professor, University of Passo Fundo, Passo Fundo, RS, Brazil. \\ 2- DDS, PhD, School of Dentistry, University of North Carolina, Chapel Hill, USA. \\ 3- DDS, PhD, Associate Professor, Department of Restorative Dentistry, Araraquara Dental School, São Paulo State University, Araraquara, SP, Brazil. \\ 4- BDS, DMD, School of Dentistry, University of North Carolina, Chapel Hill, USA.
}

Corresponding address: Mário Tanomaru-Filho - Rua Humaitá, 1680 - Centro - 14801-903 - Araraquara - SP - Brasil - Phone +55-16-3336-4658 - Fax. +5516-3301-6392 - e-mail: tanomaru@uol.com.br

Received: October 29, 2009 - Modification: March 18, 2010 - Accepted: March 27, 2010

\section{ABSTRACT}

\begin{abstract}
bjective: The aim of this in vitro study was to evaluate the bond strength of different root canal sealers to dentin. Material and Methods: Forty extracted single-rooted human teeth were examined and the coronal and middle thirds of the canals were prepared with a $1.50 \mathrm{~mm}$ post drill (FibreKor Post System, Pentron). The teeth were allocated in two experimental groups, irrigated with $2.5 \% \mathrm{NaOCl}+17 \%$ EDTA or saline solution (control group) and instrumented using Race rotary files (FKG) to a size \#40 at the working length. Then, the groups were divided into four subgroups and filled with Epiphany sealer (Group 1), EndoREZ (Group 2), AH26 (Group 3) and Grossman's Sealer (Group 4). After 2 weeks of storage in $100 \%$ humidity at $37^{\circ} \mathrm{C}$, all teeth were sectioned transversally into $2-\mathrm{mm}$ thick discs. Push-out tests were performed at a cross-head speed of $1 \mathrm{~mm} / \mathrm{min}$ using a universal testing machine. The maximum load at failure was recorded and expressed in MPa. Results: Means ( $\pm S D$ ) in root canals irrigated with $2.5 \% \mathrm{NaOCl}$ and $17 \%$ EDTA were:

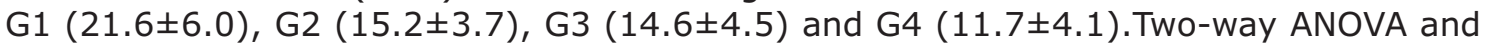
Tukey's test showed the highest bond strength for the Epiphany's group $(p<0.01)$ when compared to the other tested sealers. Saline solution decreased the values of bond-strength $(p<0.05)$ for all sealers. Conclusion: Epiphany sealer presented higher bond strength values to dentin in both irrigating protocols, and the use of $2.5 \% \mathrm{NaOCl}$ and $17 \%$ EDTA increased the bond strength values for all sealers.
\end{abstract}

Key words: Root canal obturation. Root canal filling material. Push-out.

\section{INTRODUCTION}

Adhesion of sealers to dentin is a required property for root canal sealers. Although standard organization does not provide any data concerning the minimal required bond strength for endodontic sealers, it has been subject of several studies $^{1,4,5,8-12,14,15,20,21,23,25}$.

It has been suggested that the ability of root canal sealers to adhere to core material and to dentin may result in superior sealing ability, which could reduce coronal and apical leakage ${ }^{15}$.

Differences in the adhesive properties of sealers to dentin may be expected for several reasons, including differences of root dentin between specimens, or even in different sites of the same root $^{4,21}$. The presence or absence of smear layer after root preparation has also been related as an important factor to be evaluated ${ }^{4}$ as well, the sealer's chemical composition and its interaction with the dentin ${ }^{12}$.

Several root canal sealers have been used in endodontics, from ZOE-based sealers to the epoxy-resin based sealers, all of them proposed to be used in association with gutta-percha. It has been demonstrated that ZOE-based sealers have lower bond strength to dentin, when compared to epoxy-based sealers, especially in presence of smear layer ${ }^{14}$.

Therefore, the concepts of root canal filling 
materials have changed since materials with adhesive properties have been evaluated. A synthetic polymer composite commercially known as Resilon (Pentron, Wallingford, CT, USA) has been suggested as a gutta-percha substitute. This filling material is used in association with a dual curable, polymer, composite sealer (Epyphany sealer, Pentron) which is able to bond to both core material and dentin ${ }^{24}$ forming a "monoblock" obturation.

The philosophy of adhesive root canal filling and the results obtained with Resilon/Epiphany showing its ability to prevent mainly coronal microleakage ${ }^{18,19}$, seems to be strongly altering the concepts of endodontics and the choice for filling materials. It can be seen by the number of studies ${ }^{8,10}$ and by the launching of new filling materials, such as resin-coated gutta-percha cones and dual-cure root canal sealers ${ }^{22}$, with the specific focus on obtaining a monoblock obturation. Another example of these adhesives system is EndoREZ (Ultradent, South Jordan, UT, USA). This system establishes a bond between a polybutadienedisocyanate-methacrylate resin-coated guttapercha core material and a self-priming sealer with an active ingredient of urethane dimethacrylate ${ }^{6}$.

The purpose of this study was to evaluate the bond strength of different sealers to dentin, in presence or absence of smear layer, using push-out tests. It was considered the hypotheses that bond strength of resin-based sealers is similar among them, but higher than that of ZOE-based sealer, and that bond strength of all sealers is higher in the absence of smear layer.

\section{MATERIAL AND METHODS}

Forty extracted single-rooted human teeth were used in this study, after approval by the Research Ethics Committee of the University of Passo Fundo, RS, Brazil (Process \#246/2006). The crowns of the specimens were removed at the cement-enamel junction using a diamonded disk in a low-speed hand piece. The working length was determined BY introducing a \#15K file until it reached the apical foramen, subtracting $1 \mathrm{~mm}$ from this length.

The teeth were allocated in two groups $(n=20)$. In Group A each root was irrigated with $2 \mathrm{~mL}$ of $2.5 \% \mathrm{NaOCl}$. The canals were enlarged with rotary $\mathrm{Ni}$-Ti files (Race, FKG, La-Chaux-des-Fonds, Switzerland), up to file \#40 at the working length. The coronal and middle thirds of the canals were shaped with a $1.50 \mathrm{~mm}$ post drill (FibreKor Post System, Pentron), followed by a final flush with 3 $\mathrm{mL}$ of $17 \%$ EDTA (Pulpdent Corporation, Watertown, MA, USA).

In Group B the same procedures were repeated using only saline solution $(0.9 \% \mathrm{NaCl}$, Aqualite, Chicago IL, USA) as irrigating. The root canals were dried with paper points. Then, all samples subdivided once again, into four groups $(n=5)$ and filled with different root canal sealers: Group I, Epiphany ${ }^{\mathrm{TM}}$ (Pentron), Group II, EndoREZ (Ultradent), Group III, AH 26 (Dentsply-DeTrey, Konstanz, Germany); and Group IV, Grossman's sealer (Endo Fill, Dentsply Ind. e Com. Ltda., Rio de Janeiro, RJ, Brazil).

All specimens were filled with the sealers without core material. The sealers were mixed according manufacturers' specifications and introduced into the root canals using a lentulo spiral \#40 in lowspeed handpiece.

In the Epiphany's group, primer (Epiphany Primer, Pentron,) was applied on the root canal walls using a paper point previously to the sealer fulfillment. After that, the sealer was light cured for $40 \mathrm{~s}$ in the root canal entrance.

After 2 weeks of storage in $100 \%$ humidity at $37^{\circ} \mathrm{C}$, all teeth were sectioned transversally into 2-mm-thick discs using a diamond saw (Isomet, Buehler, Lake Bluff, IL, USA). Push-out tests were performed at a crosshead speed of $1 \mathrm{~mm} / \mathrm{min}$ using a universal testing machine (Instron 4411, Instron Ltd., High Wycombe, England). The maximum load at failure (Fmax) was recorded in $\mathrm{N}$ and the bonding

Table 1- Mean (SD) in MPa for each group tested. Means with similar superscript symbols indicate non-significant differences $(p<0,01)$

\begin{tabular}{ccc}
\hline Irrigating Solution & Filling material & Mean (SD) \\
\hline $2.5 \% \mathrm{NaOCl}+17 \%$ EDTA & AH 26 & $14.6(4.5) \mathrm{a}$ \\
& Epiphany & $21.6(6.0) \mathrm{b}$ \\
& EndoRez & $15.2(3.7) \mathrm{a}$ \\
Saline solution & Grossman's sealer & $11.7(4.1) \mathrm{ac}$ \\
& AH 26 & $13.0(3.7) \mathrm{ac}$ \\
& Epiphany & $20.2(5.8) \mathrm{b}$ \\
& EndoRez & $13.2(4.2) \mathrm{ac}$ \\
\hline
\end{tabular}

Means with similar superscript symbols indicate no statistically significant differences $(p<0.01)$ 
surface $(A)$ was calculated using the equation:

$\mathrm{A}=2 \pi r \times h$

Where $n$ is the constant $3.14, r$ is the root canal space radius, and $h$ is the thickness of the slice in $\mathrm{mm}$. Then, the bond strength $(\delta)$, expressed in $\mathrm{MPa}$, was calculated using the equation:

$$
\delta=\frac{F}{A}
$$

The data were recorded and submitted to statistical analysis by two-way ANOVA and Tukey's test using the software SPSS 14.0. A significance level of $5 \%$ was set.

\section{RESULTS}

The Epiphany's group presented the highest bond strength $(p<0.01)$ of all other sealers, when using both $2.5 \mathrm{NaOCl}$ and $17 \%$ EDTA or saline solution. Irrigation only with saline decreased the bond strength to dentin of all sealers, in comparison to $2.5 \mathrm{NaOCl}$ and $17 \%$ EDTA irrigation $(p<0.05)$. Mean values (SD) expressed in MPa $(n=15)$ are shown in Table 1.

\section{DISCUSSION}

Ideally, one of the key roles of the sealer is to aggregate the root filling material and maintain it as compact mass with no gaps, which adheres to the canal walls and provides a single block configuration that seals hermetically the canal space ${ }^{16,23}$.

New materials have been developed in order to increase the sealing ability of endodontic filling materials. The goal is to create a better interface between root canal walls and sealer, resulting in less microleakage.

Although no correlation has been found so far between microleakage by the root canal filling material and the strength of the bond of the sealer to dentin in vitro, the assumption that it would reduce the leakage and also improve the stability of root canal filling are always correlated.

Different tests have been reported for bond strength evaluation. Shear strength $4,10,23,25$, microtensile 5 and even pull-out or push-out tests $1,6,8,20,23,24$ have been described as reproducible and effective for direct comparison of the results. Push-out test allows an accurate standardization of the specimens ${ }^{23}$. However, it is clear that test models cannot reproduce the exact clinical conditions, mainly because root dentin is not uniform and the surface of the canal walls prepared during the endodontic treatment differ considerably ${ }^{16,23}$. The thickness of dentin used for push-out tests has been also variable in several studies. Root slices from $0.6 \mathrm{~mm}$ to $7.0 \mathrm{~mm}^{2,23}$ have been suggested. Thin slices, around $1.0 \mathrm{~mm}$ thick, seem to be preferable in order to create a larger number of samples and also when high bond strength values are expected. Otherwise, there is a risk of sealer detachment while slicing, as reported by Gesi, et al. ${ }^{8}$ (2005). In the present study, 2-mm-thick slices were used in order to prevent premature debonding and also in accordance to Kreimer, et al. ${ }^{11}$ (2008). It was assumed that the area of bonded surface would be calculated and taken into account during the bond strength values (MPa) calculations. Although the model used in this study does not simulate clinical conditions, we tried to be as closer as possible to the reality by using root canal dentin instead of coronal dentin ${ }^{21}$. The use of coronal dentin could mask some results due to the structural differences between coronal and intra-radicular dentin ${ }^{13,23}$.

Another important point is that the coronal and middle thirds of the root were prepared with the same 1.5-mm-diameter post drill, making sure to avoid the influence of anatomical variations over the results. We strongly believe that it is one of the factors that could have influenced the results presented by Gesi, et al. ${ }^{8}$ (2005), and are clearly visible on these authors' images. On the other hand, in the present study, all samples were filled only with sealers without core material (gutta-percha or Resilon), which could explain the different results from those achieved by Gesi, et al. ${ }^{8}$ (2005) were Epiphany sealer had the lowest bond strength values and from Fisher, et al. ${ }^{5}$ (2004) were both Epiphany and EndoREZ had lower bond strength values, compared to an epoxy-resin based sealer (AH Plus).

A hypothetic explanation for our results is that the absence of the core material could allow the root canal sealer to achieve its full expansion without to be affected by the weak interface between the sealer and the core material. It could also explain the higher values obtained in this study when compared to the studies that used the same method but included the core material (gutta-percha or Resilon $)^{7,23}$, indicating that the failure on adhesion could be mainly affected in the interface sealer/ core material.

Current literature has shown the superiority of epoxy-resin based sealers in comparison to ZOEbased sealers, in terms of bonding. Our results are in agreement with those findings and partially confirm our first hypothesis. Grossman's sealer showed the lowest bond strength to dentin in absence or presence of smear layer, when compared to the resin based sealers. The bond strength values decreased when smear layer was present, independently of the sealers' composition, which is in accordance with other authors ${ }^{9,14}$ and confirm our second hypothesis. In the present study, the bond strength values of Epiphany were higher than those of other sealers, rejecting the hypothesis that all resin-based sealers would have similar bond 
strength to dentin. Epiphany's results might be explained by the bonding agent used to penetrate into de dentin tubules, forming tags $\mathbf{s}^{1,20}$. Research on the EndoREZ obturation system disclosed good hydrophilic properties, thus helping create long resin tags in radicular dentin ${ }^{17}$. However, these gaps appeared unbounded and exhibited insufficient adhesive strength, resulting in gap formation between sealer and canal walls ${ }^{3,7}$. It can explain the low bond strength for this group in our study.

Further studies including the core materials and cyclic fatigue are being performed in order to clarify the doubts resulted from this study.

\section{CONCLUSION}

Epiphany sealer presented higher bond strength values to dentin in both irrigating protocols, and the use of $2.5 \% \mathrm{NaOCl}$ and $17 \%$ EDTA increased the bond strength values for all sealers.

\section{REFERENCES}

1- Barbizam JV, Trope M, Teixeira EC, Tanomaru-Filho M, Teixeira $F B$. Effect of calcium hydroxide intracanal dressing on the bond strength of a resin based endodontic sealer. Braz Dent $\mathrm{J}$. 2008; 19:224-7.

2- Demiryürek EO, Külün KS, Yüsel G, Saraç D, Bulucu B. Effects of three canal sealers on bond strength of a fiber post. J Endod 2010;36:497-501.

3- Doyle MD, Loushine RJ, Agee KA, Gillespie WT, Weller RN, Pashley $\mathrm{DH}$, et al. Improving the performance of EndoREZ root canal sealer with a dual-cured two-step self-etch-adhesive. I. Adhesive to dentin strength. J Endod. 2006;32:766-70.

4- Eldeniz AU, Erdemir A, Belli S. Shear bond strength of three resin based sealers to dentin with and without the smear layer. J Endod. 2005;31:293-6.

5- Erdemir A, Eldeniz AU, Belli S, Pashley DH. Effect of solvents on bonding to root canal dentin. J Endod. 2004;30:589-92.

6- Fisher MA, Berzins DW, Bahcall JK. An in vitro comparison of bond strength of various obturation materials to root canal dentin using a push-out test design. J Endod. 2007;33:856-8.

7- Gillespie WT, Loushine RJ, Weller RN, Mazzoni A, Doyle MD, Waller $\mathrm{JL}$, et al. Improving the performance of EndoREZ root canal sealer with a dual-cured two-step self-etch adhesive. II. Apical and coronal seal. J Endod. 2006;32:771-5.

8- Gesi A, Raffaelli O, Goracci C, Pashley DH, Tay FR, Ferrari M. Interfacial strength of resilon and gutta-percha to intraradicular dentin. J Endod. 2005;31:809-13.
9- Gettleman BH, Messer HH, EIDeeb ME. Adhesion of root canal sealers cements to dentin with and without the smear layer. J Endod. 1991;17:15-20.

10- Hiraishi N, Papacchini F, Loushine RJ, Weller RN, Ferrari M, Pashley $\mathrm{DH}$, et al. Shear bond strength of Resilon to a methacrylatebased root canal sealer. Int Endod J. 2001;38:753-63.

11- Kremeier K, Fasen L, Klaiber B, Hofmann N. Influence of endodontic post type (glass fiber, quartz fiber or gold) and luting material on push-out bond strength to dentin in vitro. Dent Mater 2008;24:660-6.

12- Lee KW, Williams MC, Camps JJ, Pashley DH. Adhesion of endodontic sealers to dentin and gutta-percha. J Endod. 2002;28:684-8.

13- Nakabayashi N, Pashley DH. Hybridization of dental hard tissues. Tokyo: Quintessence; 2000.

14- Pecora JD, Cussioli AL, Guerisoli DM, Marchesan MA, SousaNeto MD, Brugnera Júnior A. Evaluation of Er:YAG laser and EDTAC on dentin adhesion of six endodontic sealers. Braz Dent J. 2001; $12: 27-30$.

15- Saleh IM, Ruyter IE, Haapasalo MP, Orstavik D. Adhesion of endodontic sealers: scanning electron microscopy and energy dispersive spectroscopy. J Endod. 2003;29:595-601.

16- Schwartz RS. Adhesive dentistry and endodontics. Part 2: bonding in the root canal system-the promise and the problems: a review. J Endod. 2006;32:1125-34.

17- Sevimay S, Kalayci A. Evaluation of apical sealing ability and adaptation to dentine of two resin-based sealers. J Oral Rehabil. 2005;32:105-10.

18- Shipper G, Ørstavik D, Teixeira FB, Trope M. An evaluation of microbial leakage in roots filled with a thermoplastic synthetic polymer-based root canal filling material (Resilon). J Endod. 2004;30:342-7.

19- Shipper G, Teixeira FB, Arnold RR, Trope M. Periapical inflammation after coronal microbial inoculation of dog roots filled with gutta-percha or resilon. J Endod. 2005;31:91-6.

20- Sly MM, Moore BK, Platt JA, Brown CE. Push-out bond strength of a new endodontic obturation system (Resilon/ Epiphany). J Endod. 2007;33:160-2.

21- Tagger M, Tagger E, Tjan AH, Bakland LK. Measurement of adhesion of endodontic sealers to dentin. J Endod. 2002;28:351-4. 22- Tay FR, Loushine RJ, Monticelli F, Weller RN, Breschi L, Ferrari $M$, et al. Effectiveness of resin-coated gutta-percha cones and dual cured, hydrophilic methacrylate resin-based sealer in obturating root canals. J Endod. 2005;31:659-64.

23- Teixeira CS, Alfredo E, Thomé LH, Gariba-Silva R, SilvaSousa YC, Sousa-Neto MD. Adhesion of an endodontic sealer to dentin and gutta-percha: shear and push-out bond strength measurements and SEM analysis. J Appl Oral Sci. 2009;17:129-35. 24- Teixeira FB, Teixeira EC, Thompson J, Leinfelder KF, Trope M. Dentinal bonding reaches the root canal system. J Esthet Restor Dent. 2004; 16:348-54.

25- Wachlarowicz AJ, Joyce AP, Roberts S, Pashley DH. Effect of irrigants on the shear bond strength of Epiphany sealer to dentin. J Endod. 2007;33:152-5. 